\title{
Da Modelagem Demiúrgica à Criação Divina: Semelhanças e distinções da influência platônica na obra Santo Agostinho
}

\author{
Daiane Rodrigues Costa ${ }^{1}$ \\ Nadir Antonio Pichler ${ }^{2}$
}

Resumo: Este trabalho trata das semelhanças e distinções entre a teoria platônica da fabricação do Universo e a teoria agostiniana da criação divina. Nossa finalidade é demonstrar que, apesar da forte influência do pensamento platônico para o fazer filosófico de Santo Agostinho, no que concerne a suas concepções sobre a origem do mundo ou o sentido do Ser, há distinções irreconciliáveis, pois ambos os pensadores estão dispostos em contextos distintos na tradição filosófica. Enquanto Platão ( 428-347 a.C), filósofo grego, encontra-se distante da ideia da concepção de criação ex-nihilo, enquanto que Santo Agostinho (354-430 d.C) desenvolveu sua obra numa época de ascensão da tradição judaico-cristã. Nesse caso, o texto defende a tese que Santo Agostinho distancia-se de Platão por acreditar que o mundo foi criado sem precisar de um substrato pré-existente, enquanto Platão defende que as matérias para a fabricação do deste já estavam dispostas desde a eternidade. Assim, o estudo conclui que o mundo, conforme afirmava Platão, é eterno, pois foi constituído de matérias eternas, enquanto a ideia de criação do mundo, defendida por Santo Agostinho, supõe que este veio a existir a partir do nada e através de uma matéria diferente do seu criador. Para isso, na primeira parte, reconstruímos em ideias gerais o pensamento neoplatônico de Plotino. É através do neoplatonismo que Agostinho tem contato com as ideias do próprio Platão. Eleé, portanto o ponto de conexão entre Platão e o bispo hiponense. Na sequência, adentramos nas concepções de divindade, tempo e criação/fabricação de Santo Agostinho e Platão, traçando os principais pontos e comparando-os.

Palavras-chave: Criação. Ser. Universo. Santo Agostino. Platão

\begin{abstract}
This work deals with the similarities and distinctions between the Platonic theory of the fabrication of the Universe and the Augustinian theory of divine creation. Our purpose is to demonstrate that, despite the strong influence of the Platonic thought for the philosophical making of St. Augustine, as far as his conceptions of the origin of the world or the sense of Being are concerned, there are irreconcilable distinctions, since both thinkers are disposed in contexts distinct in the philosophical tradition. While Plato (428-347 BC), a Greek philosopher, is far from the idea of the ex nihilo conception of creation, while St. Augustine (354-430 $\mathrm{AD})$ developed his work at a time of the rise of the Judeo-Christian tradition. In this case, the text defends the thesis that Saint Augustine distances himself from Plato because he believes that the world was created without needing a preexisting substratum, whereas Plato argues that the materials for the making of the latter were already disposed from eternity. Thus, the study concludes that the world, as Plato affirmed, is eternal, since it was composed of eternal matters, while the idea of creation of the world, defended by St. Augustine, assumes that it came to exist from nothing and through a different from its creator. For this, in the first part, we reconstruct in general ideas the Neoplatonic thought of Plotinus. It is through Neoplatonism that Augustine has contact with the ideas of Plato himself. He is, therefore, the point of connection between Plato and the bishop of Hyogo. In the sequence, we enter into the conceptions of divinity, time and creation / fabrication of Saint Augustine and Plato, tracing the main points and comparing them.
\end{abstract}

Key-Words: Creation. Being. Universe. Saint Augustine. Plato

\footnotetext{
${ }^{1}$ Graduada em Filosofia pela Universidade de Passo Fundo, mestranda em educação pelo PPGEDU/UPF e membra do núcleo de pesquisa em Filosofia e Educação. E-mail para contato: $<$ rodriguesdaiane14@yahoo.com>.

${ }^{2}$ Graduado em Filosofia. Mestre em Filosofia e doutor em Filosofia (PUCRS). Professor da Universidade de Passo Fundo.
} 


\section{Introdução}

A influência do pensamento de Platão nas reflexões filosóficas de Agostinho é de grande fiabilidade. Através dele, Agostinho distancia-se do maniqueísmo, centrado no materialismo e aufere teorias desprendidas do mundo sensível para uma realidade que logra-se além de um cosmos visível. Todavia, essa influência pouco acontece por via direta entre os dois pensadores. O pensamento de Platão alcança, em grande parte, Agostinho, através de seus novos reformuladores: os neoplatônicos. Por volta do século II d.C, Platão ressurgia nesse movimento, guiado por Plotino e por seu discípulo - Porfírio. Considerado o mais refinado pensamento filosófico da época. Plotino nasceu no ano 200 d.C, no Egito. Suas aulas e discursos tinham um caráter alusivo e enigmático, o que muitas vezes não entusiasmava os que estavam a sua volta. Já Porfírio, nascido no Egito no ano de 234 d.C, era sistemático a ponto de transformar (ou "traduzir" em linguagem mundana) os escritos enigmáticos de seu mestre em manuais didáticos. Tanto Plotino quanto Porfírio, anunciavam um grande desprezo pelo corpo e falavam sobre a libertação da alma do corpo decaído (BROWN, 2012 p. 110). Esse ensinamento fortemente platônico acreditava que o corpo, lugar de desejos carnais e erros, aprisionava a alma. A alma, por sua vez, era pura, perfeita e gozava de pleno saber. Por conseguinte, era tarefa de todo "amante da sabedoria" afastar o máximo possível a alma do corpo. Tarefa esta que só se realizaria plenamente com a morte. Assim:

O sentimento pungente de que o homem comum, preso ao mundo óbvio dos sentidos, move-se na penumbra e de que o saber que ele afirma possuir é meramente o estado obscuro e derradeiro de uma progressão inelutável de estágios decadentes de consciência é a marca da visão plotiniana do Universo. (BROWN, 2012, p.116).

A redescoberta de Platão parecia fundir-se com o cristianismo, em ascensão. O movimento neoplatônico combinava 
em diversos pontos com a doutrina cristã. Ambos falavam em um "mundo fora do mundo", ambos acreditavam em algo que estava para além da materialidade desse mundo. Brown (2012, p. 112, grifos do autor) destaca essa aproximação do neoplatonismo com o cristianismo mostrando que: "Cristo dissera: 'Meu reino não é deste mundo'; Platão dissera a mesma coisa sobre seu reino das ideias. Para Ambrósio, os seguidores de Platão eram os 'aristocratas do pensamento"”. Foi sobretudo Ambrósio, bispo de Milão e guia espiritual de Santo Agostinho, quem trabalhou na ideia de "cristianizar" o neoplatonismo, sendo um dos maiores estudiosos nesse assunto tanto quanto era um profundo conhecedor das obras gregas do próprio Platão. Portanto, essa era a linha que seguia o mais fino pensamento teológico/filosófico na mesma época em que Santo Agostinho chegou a um dos maiores centros intelectuais do Império Romano, a saber, Milão. Foi nesse sentido que o bispo de Hipona orientou suas reflexões.

Apesar dessa vasta confluência de ideias entre Platão, o neoplatonismo e Agostinho; o bispo hiponense não será um neoplatônico. Isso porque a vertente do pensamento cristão herdada por Agostinho, exige que distinções significativas sejam bem delimitadas. Essas distinções, por sua vez, são de caráter metafísico. Por isso, enquanto Platão trabalha com a ideia de Universo modelado e eterno, Agostinho assumirá a noção de mundo criado e temporal.

Nesse sentido, nosso texto começará com uma explanação sobre o neoplatonismo, para entender a forma como Agostinho teve acesso as ideias de Platão. Em seguida, tratamos de tópicos comparativos a noção de deus, tempo e mundo para o filósofo grego e o bispo de hiponense. O presente texto trata-se de uma pesquisa bibliográfica, de caráter exploratório. 


\section{A influência (neo) platônica na visão agostiniana}

Durante os nove anos de adesão ao maniqueísmo, Santo Agostinho aprendera que o ser misturava-se a um princípio substancial do bem e do mal. Como esse pensamento maniqueísta havia se enraizado nas reflexões de Santo Agostinho, era extremamente difícil para ele compreender a ideia cristã, de que Deus está no sujeito, porém não se fundiria com a essência do próprio. Nesse sentido, a tarefa é explicar: como Deus está dentro de todo ser e ao mesmo tempo é algo distinto desses seres? Afirma Sangalli ao discorrer sobre a influência neoplatônica na busca de Santo Agostinho pela beata vita:

A árvore não dá frutos apenas devido a seus galhos e flores. Antes disto, possui um tronco, cujas raízes estão alicerçadas em diferentes direções, para lhes dar sustentação e firmeza. Desse conjunto de elementos depende a própria possibilidade de vida, enquanto árvore, e de formação de seus frutos e, assim, a sua perpetuação pelos frutos-sementes que germinarem a seu modo e lugar. Por analogia, a grosso modo, isto pode ser aplicado a cada filósofo em seu tempo, acrescentando-se a peculiaridade e a capacidade intuitiva e reflexiva de cada um e, no caso aqui, da síntese filosófico-teológica realizada pelo cristão Agostinho de Hipona. (1998, p. 143).

A resposta àquela pergunta foi encontrada no neoplatonismo, a corrente filosófica de suma influência, mas não somente, para a construção do pensamento agostiniano.

Foi Plotino quem ajudou Santo Agostinho a solucionar esse dilema. Nesse contexto, Plotino afirma que o mundo não material não apenas existiria, mas seria fundante para o mundo material. Isso porque, tudo que existe seria uma derivação do um. O Uno seria aquela realidade que permaneceria imóvel, mas que mesmo assim seria capaz de gerar, sem ser movido, uma vez que aquilo que o Uno gera seria inferior a ele. O Uno geraria algo sem mover porque ele teria, essencialmente, uma força operante. Por sua vez, a força 
operante teria uma dupla face: (1) ela encerrar-se-ia dentro do próprio Uno; e (2) brotaria ou emanaria para fora dele.

Quando supostamente sairia do Uno já não seria uma realidade igual a ele. Desta forma, Plotino sugere a analogia do fogo para entender o Uno, cuja essência é uma e se mantém sempre a mesma. Todavia, o calor que emana do fogo, apesar de ser gerado pelo fogo, não é igual ao fogo. Assim, o Uno permaneceria o mesmo e geraria algo inferior a ele (PLOTINO apud REALE; ANTISERI, 1990, p. 342). Disso que procede do Uno nasceria a segunda realidade, o Nôus, que também pode ser traduzido por “espírito”. O Nôus nasceria quando essa matéria que sai do Uno e volta-se para contemplar aquilo que a gerou e torna-se fecunda do princípio que a gerou, surgindo, assim, o pensamento (ato de pensar) e o pensado (conteúdo do pensamento, as ideias). Por conseguinte, do mesmo modo como o Uno tornar-se espírito, ele precisaria tornar-se alma para gerar o Universo. Como ocorreria com o Uno, ocorreria com o espírito. Existiria uma força que mantém o Nôus e uma força que procederia dele. Essa força que procederia dele ao contemplar sua origem, tornar-se-ia fecunda, observando sua própria existência. Daí formar-se-ia a alma.

A especificidade da alma (anima) seria de dar vida ao cosmos sensível, defendia Plotino. Nesse sentido, segundo ele, existiria uma hierarquia de almas, da superior a inferior: (1) a alma suprema seria aquela que se mantém como pura alma, em contato direto com o Nôus; (2) a alma do todo seria aquela que dá vida ao Universo sensível e (3) existiria, por fim, as almas particulares, que seriam responsáveis por dar vida às coisas particulares do Universo, como os seres humanos, por exemplo.

O Universo, portanto, surgiria da última hipóstase, como o último e maior esforço que a alma conseguiria produzir. Nesse sentido, o mundo físico ficaria como o ponto mais distante do Uno, o sumo bem, e por isso encontrar-se-ia privado dele. "Desse modo, produto dessa atividade tão enfraquecida, a matéria não tem mais 
força para voltar-se na direção de quem a gerou para, por seu turno, contemplá-la” (PLOTINO apud REALE; ANTISERI, 199o, p. 345).

Com Plotino, Santo Agostinho vislumbrou que o mundo físico poderia ser derivado de algo não físico e completamente transcendental. Além disso, o futuro bispo de Hipona começava a desacreditar da ideia maniqueísta de que o homem é bom, mas que sua bondade vive aprisionada e oprimida por algo que o faz errar (o mal). Isso implicaria na irresponsabilidade humana do mal produzido no mundo. Nessa conjuntura, o mal era ativo e oprimia o bem, que era passivo. Nesse sentido, Plotino concedeu a Santo Agostinho um pensamento completamente diferente daquele apregoado pelos maniqueístas. No caso da teoria da teoria da processão, de Plotino, o mal seria simplesmente a privação do sumo bem $^{3}$, visto que a realidade física, exaurida como a última emanação, não teria mais forças para contemplar o Uno-bem. Portanto, os neoplatônicos, aos poucos, tornavam-se bem mais interessantes nas reflexões de Santo Agostinho do que o maniqueísmo. Ideias como a de que algo não-físico pode criar ou gerar algo físico não eram mais vistas como absurdas.

Além da influência neoplatônica ter se tornado uma base segura para que Santo Agostinho galgasse os degraus para a sua conversão ao cristianismo, outros temas tratados por Platão tiveram fortes influências nas reflexões agostinianas. Tanto Platão, quanto Santo Agostinho acreditavam que a verdade não estava no mundo exterior. Se o homem quisesse chegar à verdade era preciso olhar para dentro de si. No caso de Platão, isso ficou fortemente marcado como a teoria da reminiscência. Nela, Platão afirma que a verdade (as ideias) já estaria impressa na alma e esta, por sua vez, precisaria aos poucos ser recordada. Desta forma, quando a alma entra em

\footnotetext{
${ }^{3}$ Uma das reflexões mais conhecidas de Santo Agostinho foi sua pesquisa sobre a origem do mal. Essa vertente neoplatônica teve uma decisiva importância em seu trabalho. A única diferença é que o bispo de Hipona compreende o mal simplesmente como ausência do bem. Enquanto isso, os neoplatônicos compreendem o mal como uma substância privada do bem. Ou seja, os neoplatônicos entendem o mal ainda como uma substância, enquanto Santo Agostinho, não.
} 
contato com o corpo, já que este seria algo corrompido, ela "esqueceria" tudo o que havia contemplado no mundo inteligível. Todavia, a noção de "olhar para si” para alcançar a verdade, em Santo Agostinho, é distinta dessa abordagem (neo) platônica. Para Santo Agostinho, no diálogo De magistro (XII) O sujeito precisa olhar para si não porque sua alma já sabe e precisa ser recordada, mas porque que existiria na alma um mestre interior que ensina. Seria Cristo que estaria no homem (mas não fundindo-se nele) que diria a verdade.

\section{As diferentes concepções de "Deus" como princípio}

Tanto a filosofia cristã de Santo Agostinho como a cosmologia de Platão atribuem o princípio do mundo material a um Ser total e pleno. Segundo Ullmann (2002 apud RUBINI, 2008, p. 46) "neste particular, platônicos, neoplatônicos e cristãos se encontram. Isso significa que também existem fragmentos de verdade na filosofia pagã e nas religiões não-cristãs, os quais devem ser valorizados" ${ }^{4}$. Entretanto, seria uma visão rasa e generalizadora dizer que platonismo e neoplatonismo estão em consonância plena com o pensamento profundamente cristão de Agostinho. Há concordância no que tange a busca por um princípio transcendental para a origem do ser. No entanto, por sua vez, uma análise que esmiúça e detalha essas reflexões, percebe-se que existem pontos dissonantes e irreconciliavelmente divergentes.

Para Santo Agostinho, o mundo seria criado por um ato voluntário, livre e generoso da parte de Deus, que desejou criar o mundo. Nessa conjuntura, Deus seria aquele que teve a ideia de cada criatura e também seria ele quem executaria a ação. Assim, todo o ser também teria uma dupla existência: os seres particulares existiriam em si e na mente de divina, na qual todos os seres foram

\footnotetext{
${ }^{4} \mathrm{~A}$ intenção da citação foi destacar que, no sentido de procurar um princípio transcendental para o mundo físico, platônicos e cristãos muito se aproximam. Não é nossa intenção afirmar que a verdade está na interpretação cristã do mundo, como sugere o fim da citação.
} 
planejados. Em contrapartida, para Platão o ser que executaria a fabricação do mundo e a ideia que serviu de molde para essa fabricação são dois seres distintos. Na visão platônica de Universo, quem exerce a ação de fabricar o mundo seria o Demiurgo, mas não pertenceria a ele as ideias que serviriam de parâmetro para a sua obra. As ideias possuiriam uma realidade própria e independente do deus platônico. O esquema abaixo ilustra como o Deus cristão seria o único responsável pelo mundo físico, para Santo Agostinho, enquanto na cosmologia platônica seria preciso de mais de um ser para que isso ocorra:

\section{Esquema $\mathbf{A}^{5}$}



2. Esquema $B^{6}$



Tanto o Demiurgo quanto o Deus cristão teriam o mesmo princípio motivador para fazer o mundo. O deus platônico, por estar voltado à ideia do Bem, pretenderia multiplicá-la, reproduzi-la. Ao Deus cristão, como defende Santo Agostinho, nada se encontraria acima, a sua própria bondade seria motivo suficiente para criar algo bom. Nesse sentido ambos os “deuses” convergem, pois ambos teriam o mesmo princípio para a sua ação, a bondade.

\footnotetext{
${ }^{5} \mathrm{O}$ esquema A ilustra que as formas usadas para modelar o mundo, a ação criadora e a substância material utilizada na criação do Universo partiram de um único ser, Deus.

${ }^{6} \mathrm{O}$ esquema $\mathbf{B}$ ilustra que o mundo físico não tem origem em um único ser, como mostra o esquema A. No esquema B percebemos que o arquétipo, que serviu de molde para fazer o mundo tem existência independente em relação a quem fabrica o mundo, no caso, o Demiurgo. Além disso, a matéria utilizada para a aplicação das ideias já preexistia, diferentemente da cosmovisão cristã, que afirma que Deus criou tudo sem precisar de nada.
} 
Todavia, para os gregos, afirma Reale (2014, p. 150) a figura de deus, para os gregos, sempre esteve subordinada a algumas regras que são hierarquicamente superiores a ele. No caso da cosmologia platônica, quem estaria a cima do Demiurgo é o arquétipo. Seria o mundo inteligível, nesse caso, que determinaria a forma como o Demiurgo modelaria o mundo. Com efeito, o Demiurgo não pode ser confundido com a ideia do Bem. A ideia do Bem estaria acima do deus platônico e este deve ser entendido como "bom”. Para Platão o Demiurgo seria bom porque sempre espelhouse na ideia de bem e porque sempre procurou estar próximo dela. Portanto, a figura de deus que os gregos conheceram era infinitamente mais limitada do que o Deus cristão, que daria a lei, determinaria como a criação seria e criaria do nada.

\section{O Tempo: uma criatura independente ou simplesmente um movimento dos corpos?}

Comparado com o Deus cristão, o deus platônico seria extremamente limitado, pois sua ação estaria sempre subordinada às ideias. Nesse sentido, como o arquétipo seria o apogeu da perfeição, o Demiurgo, por ser bom, teria mirado como modelo aquilo que sempre permanece como é, ou seja, as ideias. Todavia, como o material que o Demiurgo utilizava não seria idêntico às próprias ideias, não pode ele reproduzir sua total perfeição. Nesse caso, como não pode reproduzir a eternidade das ideias, ele reproduziu um movimento eterno e contínuo, o tempo (Ti, 37a-d). Nesse contexto, o tempo é como uma consequência do Universo, pois a matéria da qual o Demiurgo fabricou o mundo degrada-se, fenece e nasce, deixa de ser aquilo que é para transformar-se em outra coisa. Assim, passa a ser fundamental a existência do tempo, pois seria um completo devaneio dizer que um movimento não pressupõe a passagem de tempo. Todo o movimento no qual caminham todos os seres sensíveis está dentro do tempo. 
Analisando a forma como Santo Agostinho e Platão entendem e concebem o tempo, em um primeiro momento, percebemos que ambos o entendem como algo que veio a existir em um determinado momento. Para Platão, não há tempo antes do mundo ser moldado e entrar em movimento. Para Santo Agostinho, não há tempo antes de Deus o ter criado:

Mas acontecia que a natureza daquele ser era eterna, e não era possível ajustá-la por completo ao ser gerado. Então, pensou em construir uma imagem móvel da eternidade, e, quando ordenou o céu, construiu, a partir da eternidade que permanece uma unidade, uma imagem eterna que avança de acordo com o número; é aquilo a que chamamos tempo. De facto, os dias, as noites, os meses e os anos não existiam antes de o céu ter sido gerado, pois ele preparou a geração daqueles ao mesmo tempo que este era constituído (Ti, 37a-e).

Nesse caso, Platão entende que o tempo é uma consequência intrínseca à ordenação do universo. O tempo não teria existência sem o Universo e o Universo não seria possível sem o tempo, nessa visão de mundo, pois se não há como reproduzir a eternidade, só restaria a opção de reproduzir o tempo. Por isso, Platão entende que o tempo seria o movimento dos corpos, visão contestada por Santo Agostinho.

Para Santo Agostinho, o tempo não está ligado com qualquer um dos outros seres, pois seria uma criatura independente:

De onde poderiam vir e como poderiam transcorrer os inumeráveis séculos, se não os tivesse criado, tu que és o autor e criador de todos os séculos? Que tempo poderia existir, se não fosse estabelecido por ti? E como poderia esse tempo transcorrer, se nunca tivesse existido? Portanto, sendo tu o criador de todos os tempos - se é que existiu algum tempo antes da criação do céu e da terra - como se pode dizer que cessavas de agir? (Conf., XI, xiii, 15). 
Assim sendo, o tempo seria uma criatura com existência independente, como são os astros celestes, os animais e assim por diante. Santo Agostinho afirma que, o movimento e transformações dos seres estão dentro do tempo, mas o tempo não se resumiria ao movimento dos corpos. Nisso, o bispo hiponense refuta Platao. Portanto, apesar de ambos os pensadores entenderem que o tempo não é eterno, mas veio a existir em um determinado momento, convergindo as duas correntes filosóficas, o distanciamento na compreensão do tempo é claro. Para Platão o tempo existe como uma consequência da fabricação do mundo. Como o filósofo grego trabalha com a ideia de um mundo que nunca se degradará, o tempo, por conseguinte, também seria infinito. Já para Santo Agostinho, o tempo foi criado como qualquer outro ser, e também pode ser destruído como todo o Universo também está sujeito, ratificando a visão profética do Apocalipse.

\section{Da fabricação cósmica à criação ex-nihilo}

Com as considerações feitas até aqui sobre o papel da figura existente de deus para Platão e para Santo Agostinho e da noção de tempo para esses dois filósofos, já possuímos informações o suficiente para compreender que a visão agostiniana acerca da criação do mundo diferencia-se consideravelmente da visão platônica. Talvez a principal distinção tenha como ponto nevrálgico as distintas ideias acerca da origem do princípio material, cuja base é importante para supor que o Universo viesse a existir. Assim, o princípio sensível, do qual o mundo é feito, tem origem distinta em relação a uma comparação da corrente de pensamento agostiniana e da corrente de pensamento platônica.

Santo Agostinho e Platão convergem, contudo, na ideia de que o Universo surgiu em um determinado momento. O responsável por esse surgimento seria um ser transcendental, imutável e perfeito. Todavia, como indicamos no início desse tópico, a concepção da origem do princípio material distancia-se de um filósofo para outro. 
Para Platão, já existiria um princípio material eterno. No entanto, esse princípio estaria em desordem, pois não tinha forma alguma definida. Nesse sentido é que Reale (2014, p. 146) destaca que o mundo seria uma "criação ao modo helênico". "Criar ao modo helênico" não compreende uma criação do nada, como estamos acostumados a pensar com a influência da visão cristã. Criar, para os gregos, seria levar algo que já existia, mas que estava em desordem, à ordem. No Timeu, Platão defende que o trabalho do Demiurgo foi dar molde a um princípio que já existia, formando os quatro princípios da matéria - terra, água, fogo e ar. A partir desses quatro elementos, todo o mundo foi fabricado.

Em contrapartida, a visão agostiniana tenta explicar literalmente a narração mitológica do livro do Gênesis de uma criação ex-nihilo (do nada). Nessa conjuntura, Deus não poderia estar subordinado a uma matéria já preexistente para criar, pois teria que se admitir que ele estaria sujeito às regras dessa matéria, sendo que ela estaria hierarquicamente superior a ele, como acontece com o Demiurgo.

O Deus cristão teria criado a partir do nada, mas como afirma Costa (2007, p. 22), não é um “nada substancial”. Deus não precisou do nada, ele criaria tudo sem necessitar de nada além de sua própria vontade. Desta forma, Santo Agostinho, fortemente influenciado pela tradição judaico-cristã, entra na história da filosofia como um filósofo que trouxe uma nova concepção para o surgimento do ser, diferente das três visões que existiam até então:

1. Idealista, protagonizada pelo platonismo, que concebe o surgimento dos seres sensíveis como fabricação do Demiurgo [...] que transforma a matéria informe e indeterminada (caos) em serem (sic), colocando nele a ideia, de tal modo que os seres sensíveis são participação no mundo inteligível ou ideal;

2. realista, propagada pelo aristotelismo, o qual defende que o mundo vive em eterna mudança, que não é senão o movimento dos seres em busca da perfeição [...], que tem seu ápice na Forma perfeita - Deus - o motor imóvel, o que significa que o surgimento 
dos seres sensíveis não é senão "formação" ou determinação da matéria [...];

3. imanentista, desenvolvida pelo neoplatonismo, que, fazendo uma junção com o idealismo platônico com o realismo aristotélico, diz que o Uno, supra-sensível e inteligível, no seu desdobramento (emanação) divide sua bondade gerando hipóstases inferiores. (COSTA, 2007, p. 22, grifos do autor).

Assim, nenhuma das três compreensões de mundo imaginava que a matéria da qual o Universo é formado poderia ter surgido do nada, colocando a cosmovisão agostiniana como algo inédito na compreensão do Universo.

\section{Considerações Finais}

Explanar duas correntes filosóficas que carregam o status de serem fundantes para as suas respectivas épocas jamais será uma tarefa simplória. Essa primeira consideração se faz necessária quando dos reportamos tanto à obra de Platão, quanto à obra de Santo Agostinho. Por isso, é importante a consciência de que essas conclusões são esquivadas de respostas definitivas, uma vez que a obra dos autores que nos propusemos analisar são tão vastas e possuem uma potencialidade reflexiva tão grande quanto perduram suas influências na história da Filosofia.

O objetivo central desse estudo, conforme exposto no decorrer do trabalho, foi confrontar o que a corrente filosófica platônica defende quando trata da questão da origem do Ser em comparação com a concepção agostiniana sobre a mesma questão. Nesse sentido, tratamos sobre as distinções e semelhanças sobre ambos os pensamentos. É necessário deixar claro que as distinções entre ambas as correntes filosóficas só é possível no âmbito micro, isto quer dizer, analisando de perto e esmiuçando tais pensamentos, uma vez que, no campo macro, elas se inserem no mesmo paradigma de um Universo perfeito e simétrico. 
Com isso, destacamos três aspectos que bastam para conferir certa ruptura no modo de pensar o Universo entre Platão e Santo Agostinho, antiguidade grega clássica e Patrística. Esses três pontos centrais que destacamos foram: o princípio que gera o mundo, o "vir a ser" do tempo e a derivação do Universo.

No que tange ao princípio causal, tanto o pensamento agostiniano quanto o pensamento platônico concebem o mundo como derivação da obra de um agente transcendente. Para Platão, quem fabrica o mundo é o Demiurgo, mas ele apenas modela o mundo. Tanto os moldes quanto a matéria que ele utiliza para fazer isso já existiam desde a eternidade. Por isso, é incorreto dizer que o Demiurgo cria. Desta forma, o deus que Platão criara era demasiadamente limitado perto do Deus cristão de Santo Agostinho. Este, supostamente, tirou do nada a matéria e deu forma a ela segundo suas próprias ideias. Ainda, o construtor do mundo, após fabricá-lo, retira-se de cena, não mais interferindo na sua obra. $\mathrm{O}$ Deus cristão, pelo contrário, é responsável pela governabilidade de sua obra até quando ela existir. Assim, afirma Costa (2007, p.16): "Nosso pensador afirma que, na primeira passagem bíblica, o "descansou" significa que Deus completou a sua obra criacional [...]. Porém, isso não significa que a criação adquiriu total autonomia diante de Deus, pois ele não cessa de governa-la [...]”.

Em relação ao tempo, Santo Agostinho, nas Confissões (XI, xxiii, 29), faz uma crítica direta ao modo como Platão o entende. Para o bispo hiponense, o tempo é uma criatura independente de qualquer outra. Enquanto Platão entende o tempo como uma consequência do movimento que começou a acontecer com a fabricação do Universo. Desse modo, enquanto existir movimento, existe também o tempo. Por sua vez, na visão de Santo Agostinho, mesmo a matéria cessando sua transformação ou degeneração (o seu movimento), o tempo continuaria presente, pois sua existência não está relacionada com nenhum outro ser material.

Ao entender a limitação dos seres transcendentais que fizeram o Universo da visão platônica em relação ao que defende a 
concepção de Santo Agostinho, é visto que há um elemento crucial a ser considerado. Em Platão, como já afirmado, os elementos que o Demiurgo utiliza para fabricar o Universo já existiam independentemente do próprio deus. As ideias, o demiurgo e o princípio material do Universo pertencem a eternidade. Nesse sentido, como tudo aquilo que forma o Universo seria eterno, o mundo também seria eterno, mesmo imerso em constantes transformações (o mundo como um movimento eterno). Mas isso não acontece com a visão agostiniana de criação. Isso porque, apesar de Santo Agostinho estar fortemente influenciado pela metafísica platônica, ele recebe a influência da cosmogonia cristã que, apesar de admitir um princípio transcendental para o mundo, ela não admite que o mundo seja produzido fora desse princípio, ou que dependa de algo exterior a ele do qual o Universo deriva. O sentido absoluto de Deus recebe maior ênfase na compreensão cristã do que na platônica. Nesse sentido, a ruptura da qual falamos diz respeito a uma mudança de olhar referente ao princípio que origina o Universo na visão de ambas as correntes filosóficas. Platão e seus contemporâneos não conheciam um Universo finito. Por sua vez, Santo Agostinho talvez tenha sido um dos primeiros filósofos a afirmar, incisivamente, que o mundo material veio a existir do nada. Isso possivelmente por o contexto histórico exigir uma grande dedicação no sentido de consolidar sua fé no ponto de vista intelectual. Segundo Matthews (2007, p. 27), “ é possível afirmar que existem bases suficientes para sustentar que nenhum teólogo fez mais do que Agostinho para estabelecer a ortodoxia cristã”. Desta forma, a visão agostiniana de Universo não está comprometida com a eternidade ou infinitude do mesmo, pois se ele veio a existir, ele pode também deixar de existir, ratificando a ideia do fim do mundo, o dia do juízo final, narrado pelo apóstolo João no livro Apocalipse. 


\section{Referências}

\section{Básica}

SANTO AGOSTINHO. Comentário ao Gênesis. Tradutor Agustinho Belmonte. São Paulo: Paulus, 2005.

. Confissões. Trad. de Maria Luisa Jardim Amarante. São Paulo: Paulus, 1984. (Coleção Patrística).

. Confissões;De magistro. Trad. de Ângelo Ricci. São Paulo: Abril Cultural, 1980. (Coleção Os Pensadores).

PLATÃO. Timeu - Crítias. Trad. de Rodolfo Lopes. Coimbra: Centro de Estudos Clássicos e Humanísticos (CECH), 2011.

\section{Complementar}

BÍBLIA. Português. Bíblia de Jerusalém. São Paulo: Paulus, 2002.

BOEHNER, Philotheus; GILSON, Etienne. História da filosofia cristã: desde as origens até Nicolau de Cusa. 3. ed. Rio de Janeiro: Vozes, 1970.

BROWN, Peter. Santo Agostinho: uma biografia. 7. ed. Rio de Janeiro: Record, 2012

COSTA, M. R. N. Tempo e eternidade em Agostinho de Hipona. In: REEGEN, J. G. J.; BONI, L. A. de; COSTA, M. R. N. (Orgs.). Tempo e eternidade na Idade Média. Porto Alegre: EST, 2007. p. 21-29

COSTA, Marcos Roberto Nunes; BRANDÃO, Ricardo Evangelista. A Teoria da Criação, Segundo Santo Agostinho. Ágora Filosófica, Pernanbuco, ano 7, n. 1, p. 7-26, Jan./Jun. de 2007.

EBEJER, Dom Walter Michael. A teoria platônica das formas: com especial referência a sua cosmologia no Timeu. União da Vitória: UNIUV, 2010.

GILSON, Étienne. Introdução ao estudo de Santo Agostinho. 2. ed. São Paulo: Discurso Editorial; Paulus, 2010. 
LOPES, Rodolfo. Introdução. In: PLATÃO. Timeu. Coimbra: Centro de Estudos Clássicos e Humanísticos, 2011. p. 12-68.

MATTHEWS, Gareth. Santo Agostinho: a vida e as ideias de um filósofo adiante de seu tempo. Rio de Janeiro: Zahar, 2007.

REALE, G. Platão. Trad. Henrique Cláudio de Lima Vaz e Marcelo Perine. 2. ed. São Paulo: Edições Loyola, 2014.

REALE, G.; ANTISERI, D. História da filosofia: antiguidade e Idade Média. 4. ed. São Paulo: Paulus, 1990.

RUBINI, Ademir. O neoplatonismo no pensamento de Santo Agostinho. 2008. Trabalho de conclusão de curso (bacharelado em Filosofia) - Universidade de Passo Fundo, Passo Fundo, 2008.

SANGALLI, Idalgo Jose. O fim último do homem: eudaimonia aristotélica à beatitude agostiniana. Porto Alegre: EDIPUCRS, 1998. 